\title{
Teamwork training with nursing and medical students: does the method matter? Results of an interinstitutional, interdisciplinary collaboration
}

\author{
Cherri Hobgood, ${ }^{1}$ Gwen Sherwood, ${ }^{2}$ Karen Frush, ${ }^{3}$ David Hollar, ${ }^{4}$ Laura Maynard, ${ }^{5}$ \\ Beverly Foster, ${ }^{2}$ Susan Sawning, ${ }^{6}$ Donald Woodyard, ${ }^{6}$ Carol Durham, ${ }^{2}$ \\ Melanie Wright, ${ }^{7}$ Jeffrey Taekman, ${ }^{7}$ on behalf of the Interprofessional Patient Safety \\ Education Collaborative
}

\begin{abstract}
${ }^{1}$ UNC School of Medicine, Department of Emergency Medicine, Chapel Hill, North Carolina, USA

${ }^{2}$ UNC School of Nursing, Chapel Hill, North Carolina, USA ${ }^{3}$ Duke University School of Medicine and Duke University Health System, Durham, North Carolina, USA

${ }^{4}$ UNC School of Medicine, Department of Medicine, Chapel Hill, North Carolina, USA ${ }^{5}$ Duke University Office of Patient Safety, Durham, North California, USA

${ }^{6}$ UNC Clinical Skills and Patient Simulation Center, Chapel Hill, North Carolina, USA 7 Duke University School of Medicine, Department of Anesthesiology, Durham, North Carolina, USA
\end{abstract}

\section{Correspondence to}

Dr Cherri Hobgood, UNC School of Medicine, Department of Emergency Medicine, CB 7594, UNC Hospitals, Chapel Hill, NC 27599, USA;

hobgood@med.unc.edu

The Interprofessional Patient

Safety and Education

Collaborative is an

interdisciplinary,

interinstitutional team focused on improving patient safety and team training education. Its members are: B Foster, B

Goldstein, C Durham, C Mayer, C Grochowski, D Hollar, A Felix,

G Sherwood, C Hobgood, D Woodyard, H Love, J Taekman, P Kinneer, K Frush, K Turner, L Cronenwett, M Holtschneider, M Wright, N Segall, C Osmond, V Kaprielian, S Sawning, L Maynard and S Promes.

Accepted 3 November 2009 Published Online First 27 April 2010

\begin{abstract}
Objectives The authors conducted a randomised controlled trial of four pedagogical methods commonly used to deliver teamwork training and measured the effects of each method on the acquisition of student teamwork knowledge, skills, and attitudes.

Methods The authors recruited 203 senior nursing students and 235 fourth-year medical students (total $\mathrm{N}=438$ ) from two major universities for a 1-day interdisciplinary teamwork training course. All participants received a didactic lecture and then were randomly assigned to one of four educational methods: didactic (control), audience response didactic, role play and human patient simulation. Student performance was assessed for teamwork attitudes, knowledge and skills using: (a) a 36-item teamwork attitudes instrument (CHIRP), (b) a 12-item teamwork knowledge test, (c) a 10-item standardised patient (SP) evaluation of student teamwork skills performance and (d) a 20-item modification of items from the Mayo High Performance Teamwork Scale (MHPTS).
\end{abstract}

Results All four cohorts demonstrated an improvement in attitudes $\left(F_{1,370}=48.7, p=0.001\right)$ and knowledge $\left(F_{1,353}=87.3, p=0.001\right)$ pre- to post-test. No educational modality appeared superior for attitude $\left(F_{3,370}=0.325, p=0.808\right)$ or knowledge $\left(F_{3,353}=0.382\right.$, $\mathrm{p}=0.766)$ acquisition. No modality demonstrated a significant change in teamwork skills $\left(F_{3,18}=2.12\right.$, $\mathrm{p}=0.134$ ).

Conclusions Each of the four modalities demonstrated significantly improved teamwork knowledge and attitudes, but no modality was demonstrated to be superior. Institutions should feel free to utilise educational modalities, which are best supported by their resources to deliver interdisciplinary teamwork training.

Individual and group cognitive processes ${ }^{1}$ and teamwork interactions ${ }^{23}$ all contribute to the safety of healthcare environments. Human-factors engineers in military systems have developed effective teamwork training curricula for military applications, successfully converting high-risk organisations into high-reliability ones. ${ }^{4-6}$ To develop such education for healthcare, the Agency for Healthcare Research and Quality (AHRO) funded the development of the TeamSTEPPS Patient Safety Program, derived from training materials from US Army Aviation, the US Department of
Defense, the Institute of Medicine, ${ }^{78}$ Tactical Team Decision-Making under Stress ${ }^{9}$ and MedTeams. ${ }^{10} 11$ The TeamSTEPPS programme is designed to improve care and patient safety through improved teamwork training to enhance provider communication skills. While the $7 \mathrm{~h}$ multidisciplinary TeamSTEPPS programme has proven very effective, questions remain regarding the most effective and cost-efficient approach to providing this content to learners at all stages of the health-education continuum.

Various educational approaches have been used to address training in team coordination skills in healthcare. Methods such as crisis resource management training using high fidelity human patient simulation provide realism and interactivity. ${ }^{1-3}$ However, this training modality is both costly and time-consuming, with one instructor per five trainees costing as much as $\$ 5000$ per day. ${ }^{12}$ Because of this, medical and nursing schools are implementing more traditional didactic approaches to teaching team coordination skills as well as computer-based instruction, small-group sessions, analysis of videotaped team coordination scenarios and workplace practice experiences. ${ }^{10} 11$ 13 Questions remain about the effectiveness of any of these methods to achieve the necessary changes in student attitudes, knowledge and skills, and there is little evidence for selecting particular methods. Therefore, this study was designed and implemented to adapt the TeamSTEPPS content to pre-licensure nursing and medical students, and measure the effectiveness of four educational interventions at teaching this material.

\section{METHODS}

\section{Protocol}

We conducted a full-day teamwork training and assessment exercise for 438 students composed of fourth-year medical students $(\mathrm{N}=235)$ and finalsemester nursing students ( $N=203)$ from four health-professional schools at two major universities: all students convened on the one campus where they were randomised to one of four educational intervention groups. Students were offered the option of not participating in the research project but could not decline the educational experience. Institutional review boards of both universities approved the project. 
The day-long pre-postintervention study design followed the protocol in figure 1. All participants attended a 90 min didactic lecture providing an overview and framework of teamwork training. The lecture focused on three core components of the TeamSTEPPS curriculum including: Situational Awareness, Shared Mental Model and Leadership. The content highlighted the utility of Briefs, Call-outs, Check-back and De-briefs for given patient encounters, and the advantages of using SBAR and CUS words as tools for communication among team members. Students then separated into assigned groups to participate in one of four instructional modalities: (a) high-fidelity humanpatient simulation ( $n=80$ equally divided by discipline); (b) role play ( $n=80$, equally divided by discipline); (c) audience response system lecture $(n=140)$; and (d) traditional didactic lecture $(n=138)$. All four of the instructional modalities provided an additional $60 \mathrm{~min}$ of teamwork training. Participants were rerandomised by cohort for team-based standardised patient (SP) assessments, most of which were videotaped for later scoring. To measure changes in student teamwork knowledge and attitudes, written knowledge and attitudes instruments were given as a pre- and post-test at the beginning and end of the day. Both medicine and nursing faculties were trained to lead the simulations and role plays in a $2 \mathrm{~h}$ faculty development session focused on facilitation, core TeamSTEPPS content and the case studies.

\section{Cohort A: high-fidelity human patient simulation}

Teams composed of four students, two medical and two nursing, participated in two interactive patient care scenarios based on core concepts of the didactic training. A combination of 10 METI ECS and Laerdal SimMan human simulators operated simultaneously so that 80 students completed the simulation exercises in a $2 \mathrm{~h}$ period. Each simulation exercise included preprogrammed scenarios to create a realistic patient interaction, with a faculty facilitator who played a 'confederate' role in the

Random assignment of $\mathrm{n}=438$ medical and nursing students into four cohorts, with proportionate representation of student disciplines \& universities per group

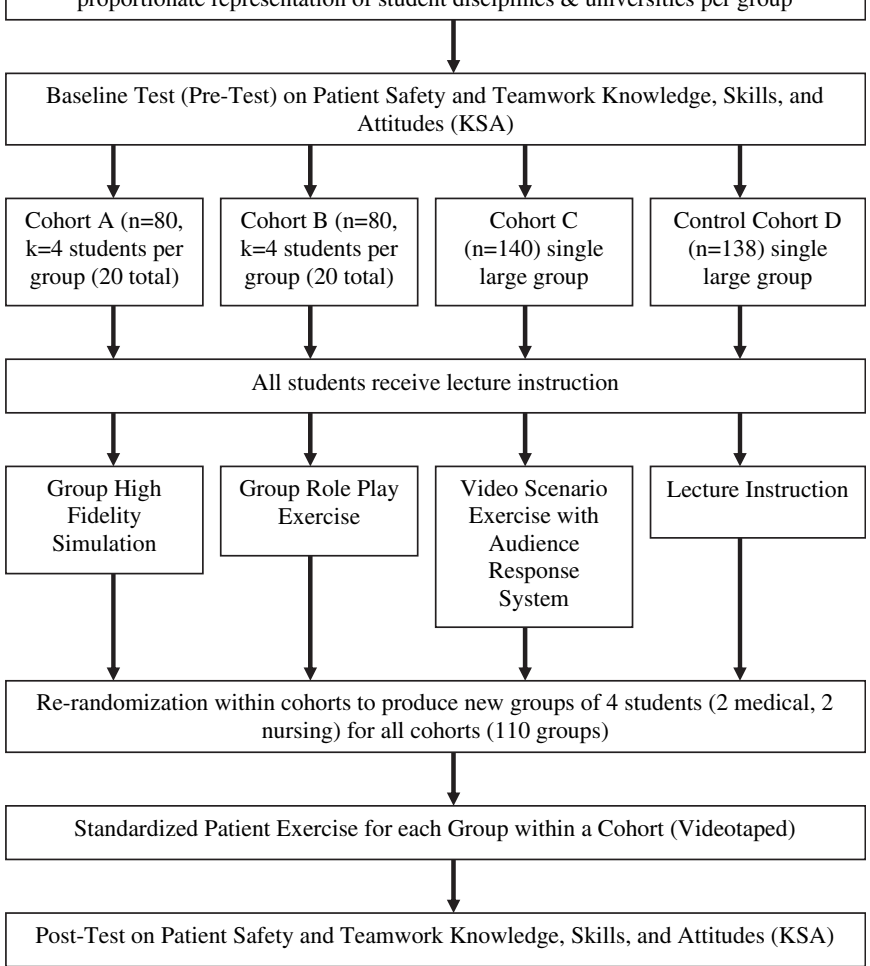

Figure 1 Research evaluation design. scenario. Sessions were video-recorded using the B-Line Clinical Skills System to allow immediate debriefing with the faculty facilitator. Although clinical actions and outcomes were addressed, debriefing focused on team cooperation and behaviours encouraged in the didactic lecture.

\section{Cohort B: low-fidelity simulation role play}

Over a $2 \mathrm{~h}$ period, 10 concurrent groups of role play participants $(\mathrm{N}=79)$ worked in four-person teams of two medical and two nursing students with the same two scenarios used in the highfidelity simulation. Scenarios were paper-based and performed as a true role play with cards and visual prompts but no mannequin. The faculty facilitator helped progress the scenario by distributing cue cards with patient information to individual team members. Participants in Cohort A and B wore disposable lab coats labelled for their role as a charge or floor nurse, and as a medical intern or chief resident to enhance the realism of the environment and to identify team members. After each role play, the faculty facilitator debriefed participants on team behaviours as above.

\section{Cohort C: audience-response didactic}

One large group of participants $(\mathrm{N}=140)$ attended a lecture that included videotaped scenarios from the TeamSTEPPS curriculum and, while differing from simulation materials, emphasised the same teamwork skills. An Audience Response System (ARS) was used to capture and display the participants' anonymous responses for group discussion. Group discussion focused on key points to enhance student understanding of key teamwork behaviours.

\section{Cohort D: didactic lecture alone}

Participants remained in a large auditorium $(\mathrm{N}=138)$ to watch the same lecture slides and TeamSTEPPS video as Cohort C participants, but without the ARS interactive slides. The faculty presenter answered any questions by students but did not initiate questions or facilitate ongoing dialogue about the material being covered. This cohort served as the control group for the study.

\section{Standardised patient teamwork skills assessments}

For the day's last activity, students were randomised into 110 new four-member teams from within their original cohort. Each group, of two nursing and two medical students, participated in a 20 min standardised patient (SP) exercise designed to elicit teamwork skills. Each participant was provided essential information needed by the team in order to treat the patient successfully and do a handoff from Nurse A/Doctor A to Nurse B/Doctor B. Participants shared their information with the team, completed a focused patient history and physical exam, and completed orders for the patient. The SP scored the team using a 10-item behaviourally anchored checklist. All participating SPs completed a $6 \mathrm{~h}$ training session with case specifics and scoring metrics. SPs were blinded to the student identity and training modality. Using the B-Line Clinical Skills System, 88 SP sessions were videotaped, representing a random sample of the four cohorts.

\section{MEASURES}

Four instruments were developed to measure teamwork knowledge, skills and attitudes: a 36-item CHIRP-Teamwork Attitudes instrument, a 12-item Teamwork Knowledge test (multiple versions), a 10-item case specific Standardised Patient 
Evaluation (SPE) of teamwork skills performance, and a 20-item modification of the Mayo High Performance Teamwork Scale (MHPTS).${ }^{14}$ The knowledge and CHIRP attitudes instruments were completed by participants, and the SPE instrument was completed by the standardised patient upon case conclusion. The modified High Performance Teamwork Scale was completed by an independent scorer while viewing the videotaped scenarios.

We originally used the first eight items of the published, 16item Mayo HPT Scale (MHTPS), ${ }^{13}$ with two items split into four items to bring the total to 10 items. A pre-hoc analysis of 20 randomly selected videotapes were scored on these preliminary 10 items by seven trained raters. Based upon interrater reliabilities (range 0.360 to 0.670 on seven items with the remaining three items at $-0.665,0.063$ and 0.182 ), the scale was modified to 20 items. A different set of 32 randomly selected videotapes (stratified across educational intervention cohorts) were scored on the revised 20 items by four new, trained raters to assess reliabilities, with results described below.

\section{ANALYSES}

All analyses were conducted using SPSS, Version 16.0 (SPSS, Chicago, Illinois). For the pretest-post-test comparisons on the Attitudes and Knowledge tests, repeated-measures Generalised Linear Model (GLM) analyses of variance (ANOVA) were conducted to compare all four cohorts (Simulation, Role play, Audience Response Simulation, Lecture) or comparisons of composite groups (eg, Simulation combined with Role play (Interactive) vs Audience Response combined with Lecture (Didactic) comparisons). These were planned comparisons based upon the Research Design (figure 1)

For teamwork skills, two evaluation methods were used: a SP Patient Checklist and an independently scored Mayo HPT scale. For the SP Evaluation, the standardised patients evaluated each of the 110 afternoon teams using the 10-item Standardised Patient Checklist for Teamwork Skills (table 1). Complete data were available for 68 teams across the four cohorts, and given the number of comparisons 64 error degrees of freedom were used in the SPSS one-way ANOVA.

Table 1 Sample items from the four measurement scales

\begin{tabular}{|c|c|c|c|c|c|c|}
\hline \multicolumn{2}{|c|}{ Collaborative Healthcare Interdisciplinary Relationship Planning Scale } & \multicolumn{5}{|c|}{ Level of agreement } \\
\hline 1 & $\begin{array}{l}\text { I must consider the interests of every professional, patient, and family member involved in } \\
\text { a medical decision }\end{array}$ & 1 & 2 & 3 & 4 & 5 \\
\hline 2 & $\begin{array}{l}\text { When making treatment decisions, I consider the perspectives of the patient and their family } \\
\text { as well as other disciplines involved in their care }\end{array}$ & 1 & 2 & 3 & 4 & 5 \\
\hline 3 & $\begin{array}{l}\text { Pharmacists, nurses, physicians, social workers and other healthcare professionals are of } \\
\text { equal importance in providing patient care }\end{array}$ & 1 & 2 & 3 & 4 & 5 \\
\hline 4 & I need the expertise of healthcare professionals from other disciplines to provide patient care & 1 & 2 & 3 & 4 & 5 \\
\hline 6 & I enjoy volunteering my ideas and expertise to group projects & 1 & 2 & 3 & 4 & 5 \\
\hline
\end{tabular}

Teamwork knowledge test

1 A nurse taking care of a baby found the baby with an abnormal appearance. She felt it was important to have the baby's physician take a look at her immediately. When she found the physician, he was on the phone. The nurse should:

a. Leave and check back later

b. Leave the number with someone else in the unit to have the c physician call her when he is finished

c. Tell the physician 'Something is wrong. I'm not sure what it is, but I need you right now'

d. Wait for the physician to finish his phone call

During a surgical procedure, a surgeon asked a circulating nurse for a medication not available in the operating room. The nurse should:

a. Leave the room and quickly bring back the medication

b. Read the medication name to the anaesthesiologist and then go to pick up the medication

c. Repeat back to the surgeon the medication name, and then go to pick up the medication

d. Repeat the medication name to himself several times and go to pick up the medication

A woman in the 41 st week of her pregnancy arrives at the labour and delivery unit, as her membranes spontaneously rupture. A triage nurse takes her vital signs and checks the fetal heart rate. The patient's blood pressure is $170 / 98$. The nurse should:

a. Document this information in the patient's chart

b. Inform both the intern and the attending physician who take care of the patient of her blood pressure

c. Inform only the intern about the patient's blood pressure, since the physician is very busy

d. Try to comfort the patient, since the elevated blood pressure may be due to discomfort from contractions

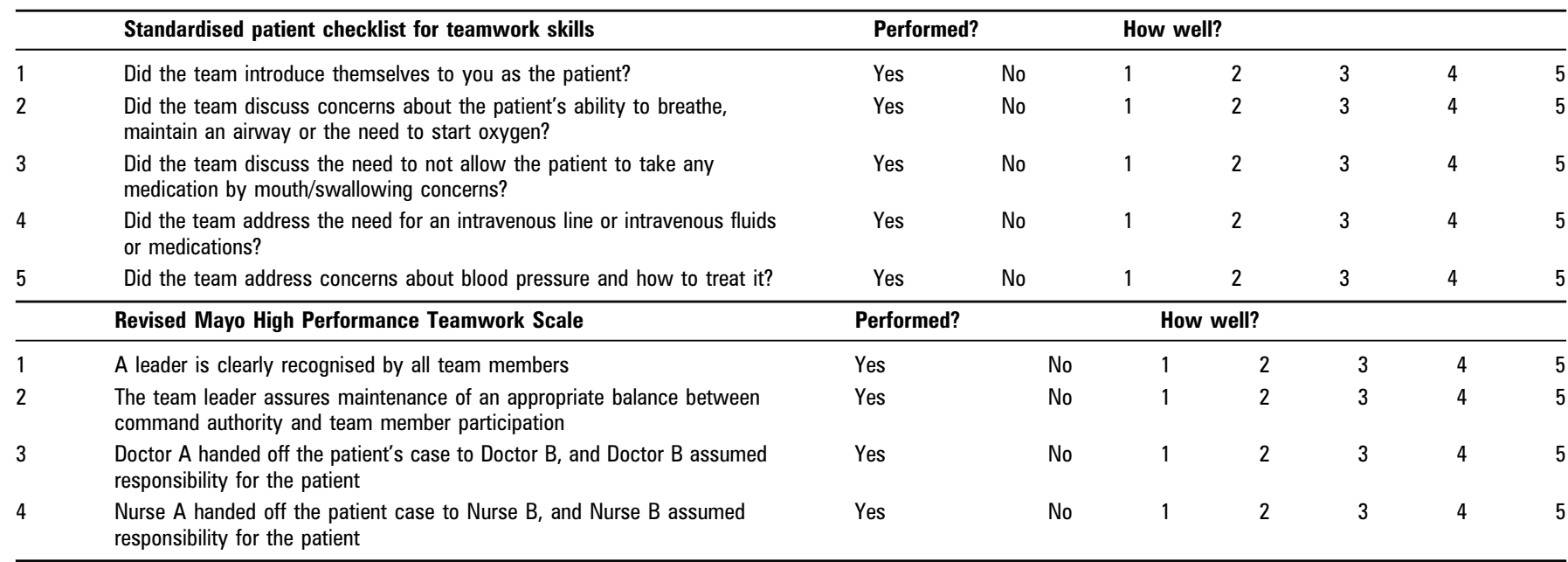


For the 20-item revised version of the Mayo HPT Scale (MHTPS) instrument, independent raters scored 32 teams evenly divided across the four cohorts. On this one-way ANOVA, complete data were available on 22 teams, and given the number of comparisons 18 error degrees of freedom were used.

\section{RESULTS}

The sample included 429 consenting students, and analyses were based on up to 370 sets of complete data (86.2\%), depending on the measurement instrument. Because of the pre-post comparison design, any surveys that could not be paired with the companion instrument (pre and post) were excluded.

Participants' attitudes towards teamwork improved significantly from pre- to post-test $\left(\mathrm{F}_{3,370}=48.7, \mathrm{p}=0.001\right)$ in all four cohorts (table 2a). When compared by educational methods, there were no significant differences between cohorts $\left(\mathrm{F}_{3,370}=0.325, \mathrm{p}=0.808\right)$. Additionally, there were no significant differences between the interactive and didactic groups $\left(\mathrm{F}_{1,372}=0.068, \mathrm{p}=0.794\right)$, between the simulation and role play cohorts $\left(\mathrm{F}_{1,126}=0.779, \mathrm{p}=0.379\right)$ and between the ARS and lecture only (control group) cohorts $\left(\mathrm{F}_{1,244}=0.273, \mathrm{p}=0.602\right)$ (table $2 \mathrm{a}$ ). The mean scores and SEs for these comparisons are provided in table $2 b$.

Participant scores on the knowledge post-test were significantly higher than pre-test scores (10.16 vs 9.13; $\mathrm{F}_{3,353}=87.3$, $\mathrm{p}<0.001$ ) (table $3 \mathrm{a}$ ); mean scores and SEs per cohort are provided in table $3 b$. However, there were no significant differences between the interactive and didactic groups $\left(F_{1,355}=0.200\right.$, $\mathrm{p}=0.655)$, between the simulation and role play cohorts $\left(\mathrm{F}_{1,93}=0.006, \mathrm{p}=0.938\right)$ and between the Audience Response System (ARS) and lecture only (control group) cohorts $\left(\mathrm{F}_{1,260}=1.08, \mathrm{p}=0.300\right)$ (table $\left.3 \mathrm{a}\right)$. The mean scores and SEs for these comparisons are provided in table $2 b$.

The SP evaluation of teamwork skills showed excellent interrater reliability between clinician raters and standardised patient scores, ranging from 0.683 to 0.968 ; therefore the standardised patient scores were used. There were no significant differences between the four cohorts (68 teams across the four cohorts) in SP ratings of teamwork skills on the 10 -item scale or for nonparametric item-by-item comparisons (table 4).

Table 2 Pre-to-posttest ANOVA comparison of teamwork attitudes across cohorts and subcohorts

\begin{tabular}{|c|c|c|c|c|c|c|}
\hline \multicolumn{3}{|c|}{ Evaluation measure } & & $\mathbf{F}$ & df & p Value \\
\hline \multirow[t]{2}{*}{1} & \multirow{2}{*}{\multicolumn{2}{|c|}{$\begin{array}{l}\text { CHIRP Attitudes-All } \\
\text { Four Cohorts }\end{array}$}} & Time & 48.71 & 1370 & 0.000 \\
\hline & & & Time $\times$ cohort & 0.325 & 3370 & 0.808 \\
\hline \multirow[t]{2}{*}{2} & \multirow{2}{*}{\multicolumn{2}{|c|}{$\begin{array}{l}\text { CHIRP attitudes-interactive } \\
\text { (A/B) versus didactic (C/D) }\end{array}$}} & Time & 48.52 & 1372 & 0.000 \\
\hline & & & Time $\times$ cohort & 0.068 & 1372 & 0.794 \\
\hline \multirow[t]{2}{*}{3} & \multirow{2}{*}{\multicolumn{2}{|c|}{ CHIRP attitudes - Sim versus role play }} & Time & 26.03 & 1126 & 0.000 \\
\hline & & & Time $\times$ cohort & 0.779 & 1126 & 0.379 \\
\hline \multirow[t]{2}{*}{4} & \multirow{2}{*}{\multicolumn{2}{|c|}{$\begin{array}{l}\text { CHIRP attitudes - Audience Response } \\
\text { System versus lecture }\end{array}$}} & Time & 29.27 & 1244 & 0.000 \\
\hline & & & Time $\times$ cohort & 0.273 & 1244 & 0.602 \\
\hline \multicolumn{7}{|c|}{ Cohort means } \\
\hline & & Time 1 & & Time & & \\
\hline \multicolumn{2}{|c|}{ Cohort } & Mean & SE & Mean & & SE \\
\hline \multicolumn{2}{|c|}{ A. Simulation } & 143.2 & 1.439 & 145.8 & & 1.540 \\
\hline \multicolumn{2}{|c|}{ B. Role play } & 142.0 & 1.508 & 145.7 & & 1.614 \\
\hline \multicolumn{2}{|r|}{ C. Audience response } & 139.8 & 1.062 & 142.9 & & 1.137 \\
\hline \multicolumn{2}{|c|}{ D. Lecture } & 141.4 & 1.062 & 144.0 & & 1.137 \\
\hline
\end{tabular}

CHIRP, Collaborative Healthcare Interdisciplinary Relationship Planning.
Table 3 Pre-to-posttest ANOVA comparison of teamwork knowledge across cohorts and subcohorts

\begin{tabular}{lllccc}
\hline Evaluation measure & & F & df & p Value \\
\hline 1 & Knowledge-all four cohorts & Time & 87.3 & 1353 & 0.000 \\
& & Time $\times$ cohort & 0.382 & 3353 & 0.766 \\
2 & Knowledge-interactive & Time & 87.5 & 1355 & 0.000 \\
& (A/B) versus didactic (C/D) & Time $\times$ cohort & 0.200 & 1355 & 0.655 \\
3 & Knowledge-Sim versus role play & Time & 19.7 & 193 & 0.000 \\
& & Time $\times$ cohort & 0.006 & 193 & 0.938 \\
4 & Knowledge-Audience Response & Time & 103.9 & 1260 & 0.000 \\
& System versus lecture & Time $\times$ cohort & 1.08 & 1260 & 0.300 \\
5 & Knowledge-lecture versus & Time & 106.2 & 1355 & 0.000 \\
& experimental & Time $\times$ cohort & 0.424 & 1355 & 0.515 \\
\hline
\end{tabular}

Cohort means

\begin{tabular}{llllll}
\hline & \multicolumn{2}{l}{ Time 1 } & & \multicolumn{2}{c}{ Time 2 } \\
\cline { 2 - 3 } & Mean & SE & & Mean & SE \\
\hline A. Simulation & 9.35 & 0.185 & & 10.2 & 0.205 \\
B. Role play & 9.15 & 0.236 & & 9.81 & 0.259 \\
C. Audience response & 9.22 & 0.143 & & 10.3 & 0.171 \\
D. Lecture & 8.88 & 0.186 & & 10.2 & 0.093 \\
\hline
\end{tabular}

The revised, 20-item Mayo High Performance Teamwork Scale demonstrated inter-rater reliabilities with Interclass Correlation Coefficients (ICC) ranging from 0.83 to 1.0 , on 19 of the 20 items. There were no differences between the four cohorts (eight teams per cohort for a total of 32 teams assessed) using one-way ANOVA $\left(\mathrm{F}_{3,18}=2.12, \mathrm{p}=0.134\right)$ (table 5 ). Examination across raters showed no significant differences on any of the 20 checklist items between the four cohorts. Sample items from all instruments used are demonstrated in table 1.

\section{DISCUSSION}

Healthcare professions students must have the tools and methods to improve teamwork skills if they are to become safe providers in our ever-more complex healthcare system. The TeamSTEPPS curriculum was designed to provide this training, and our results demonstrate that even brief teamwork training using the TeamSTEPPs curriculum significantly improves student attitudes and knowledge about team skills. The lack of substantial differences between educational methods suggests that, at least for basic teamwork training, any fidelity of training environment or educational pedagogy can provide substantial increases in basic learner competency in core teamwork knowledge and attitudes. This is important because it liberates educators and institutions from the belief that effective training in basic teamwork knowledge, attitudes and skills is only possible with expensive interventions or high-fidelity simulations.

Beaubien and Baker ${ }^{15}$ have identified three principal-components of simulation fidelity: equipment, environment and psychological fidelity. They argue that the most applicable

Table 4 Total score comparisons for standardised patient evaluation (10 items)

\begin{tabular}{lllllll}
\hline & Scale & Mean & SD & F & df & p Value \\
\hline 1 & All groups & 8.308 & 1.353 & 0.907 & 3,64 & 0.238 \\
2 & Simulation & 8.667 & 1.047 & & & \\
3 & Role play & 8.000 & 1.683 & & & \\
4 & Audience response & 8.053 & 1.545 & & & \\
5 & Lecture & 8.476 & 1.123 & & & \\
\hline
\end{tabular}


Table 5 Cohort comparisons for revised Mayo High Performance Teamwork Scale (20 items)

\begin{tabular}{|c|c|c|c|c|c|c|}
\hline & Scale & Mean & SD & $\mathbf{F}$ & df & p Value \\
\hline \multirow[t]{5}{*}{ A } & All items & 19.70 & 0.367 & 2.12 & 3,18 & 0.134 \\
\hline & Simulation & 19.88 & 0.189 & & & \\
\hline & Role play & 19.92 & 0.144 & & & \\
\hline & Audience response & 19.50 & 0.524 & & & \\
\hline & Lecture & 19.50 & 0.326 & & & \\
\hline \multirow[t]{21}{*}{ B } & Individual items & & & $\chi^{2}$ & df & p Value \\
\hline & 1 & & & 0 & 3 & 1.00 \\
\hline & 2 & & & 5.47 & 3 & 0.141 \\
\hline & 3 & & & 0 & 3 & 1.00 \\
\hline & 4 & & & 2.96 & 3 & 0.398 \\
\hline & 5 & & & 0 & 3 & 1.00 \\
\hline & 6 & & & 0 & 3 & 1.00 \\
\hline & 7 & & & 4.37 & 3 & 0.224 \\
\hline & 8 & & & 0 & 3 & 1.00 \\
\hline & 9 & & & 0 & 3 & 1.00 \\
\hline & 10 & & & 5.47 & 3 & 0.141 \\
\hline & 11 & & & 2.68 & 3 & 0.444 \\
\hline & 12 & & & 0 & 3 & 1.00 \\
\hline & 13 & & & 0 & 3 & 1.00 \\
\hline & 14 & & & 0 & 3 & 1.00 \\
\hline & 15 & & & 0 & 3 & 1.00 \\
\hline & 16 & & & 0 & 3 & 1.00 \\
\hline & 17 & & & 3.48 & 6 & 0.746 \\
\hline & 18 & & & 4.80 & 3 & 0.187 \\
\hline & 19 & & & 10.4 & 3 & 0.583 \\
\hline & 20 & & & 0 & 3 & 1.00 \\
\hline
\end{tabular}

component of teamwork training, psychological fidelity, can be achieved in low-technology simulation environments. ${ }^{15} 16$ Our study shows that neither interactive lecture nor low- or high-fidelity simulation is more effective in improving basic teamwork training in inexperienced healthcare providers than traditional didactic education alone. These results indicate that any of the four options tested are viable methods to teach teamwork concepts. One should not interpret these results as reducing the potential role of simulation, but they do raise questions about whether simulation is necessary to achieve measurable results, particularly for basic team training. Institutions with limited resources for creating high-fidelity simulation environments should not be deterred from implementing teamwork training via any method.

Our study was enriched by its interdisciplinary cohort of students and faculty from two disciplines and two universities. Faculty facilitators reported comments from student participants that they learnt first hand about each other's roles and training. Opportunities to clarify misperceptions and begin to form trusting relationships can help establish an environment of mutual respect before students work together in the clinical arena. This knowledge may assist in mitigating poor working relationships between providers which are a known factor in nurse turnover and the growing national nursing shortage. ${ }^{17}$ Although we cannot demonstrate this with our results, our anecdotal feedback suggests that our students' awareness of the importance of other members of the healthcare team was enhanced by the experience of learning together.

Our study focused on teaching students a process for a structured approach to teamwork communication skills using methods such as SBAR and CUS words as well as structured interventions such as Briefs, Call-outs, Check-back, and
De-briefs. There are limited data to assist educators in the design and the allocation of curriculum time and resources required to teach these skills to senior level physician and nursing students. Studies of the doctor patient relationship have demonstrated that complex perceptual skills require years and perhaps a lifetime to master, while process skills can be taught and learnt in brief interventions. ${ }^{18}$ Our study has demonstrated that the basic structured methods of teamwork communication can be taught and learnt using focused educational interventions comprising any of the four pedagogical methods examined in this investigation. We did not evaluate the retention of these skills or, more importantly, assess their application in real-world clinical settings; however, we have demonstrated that the critical first steps of awareness and basic knowledge can be achieved even with brief timelimited interventions.

The design of the study may have limited its ability to discern significant differences in the effectiveness of the educational interventions. Participants were randomised into cohorts without considering individual learning styles or preferences, which could have flattened the results. In addition, because this was a new deployment of this content for all schools, we did not have a working baseline from which to judge the level of content. We attempted to assess this with the pre-post design however; our preknowledge scores were higher than those predicted by faculty who designed the instrument. This may have represented a level of content expertise that we did not predict given that none of the four participating schools formally taught this content in their curriculum, or it may have represented a failure of the instrument to discriminate between learners. Second, a lack of TeamSTEPPS specific instruments limited our confidence in scoring team behaviours. In addition, many participants had no previous experience with standardised patients or high-fidelity simulation prior to the training, and this could have hindered the expression of teamwork skills, which more experienced simulation learners may have demonstrated. Further, the time allotted for students to participate in the simulated scenarios (30 min per scenario, $1 \mathrm{~h}$ total) was limited, and this may have negatively affected the educational effect of the interactive experiences. Finally, the learners were not observed longitudinally, and questions remain about the impact of various pedagogies in changing long-term behaviours in clinical situations. Subsequent measures of skill retention some days or weeks after the intervention would have strengthened our results.

\section{CONCLUSIONS}

This is the largest study to date comparing four pedagogical methods of teamwork training, a critical component of modern healthcare curricula. All the modalities appeared effective in changing knowledge and attitudes, and providing this education in a multidisciplinary manner produced a rich educational milieu for both the learners and educators. Institutions interested in team training should not feel limited to a specific fidelity of training environments; rather, medical and nursing schools should use this material in an integrated curriculum to achieve critical change in students' capacity to form effective healthcare teams. Longitudinal studies are needed to evaluate the most effective pedagogies for changing behaviour in the clinical setting.

Acknowledgements We gratefully acknowledge the support of METI, Inc. (Sarasota, Florida) and Laerdal Medical, Inc. (Wappingers Falls, New York), who provided simulators for the project, and B-Line Medical, LLC (Washington, DC) who provided technical support for performance monitoring. 
Funding The Galaxo Smithkline Foundation Research Triangle Park Durham, North Carolina.

\section{Competing interests None.}

Ethics approval Ethics approval was provided by the UNC Health affairs IRB and Duke University Health Affairs IRB.

Contributors All authors conceived the project and contributed substantially to implementation. DH, MW and JT provided data and analysis. CH, DH, GS and KF drafted the manuscript. All authors contributed to revisions and take responsibility for the manuscript as a whole.

Provenance and peer review Not commissioned; externally peer reviewed.

\section{REFERENCES}

1. McNeil BJ, Pauker SG, Sox HC Jr, et al. On the elicitation of preferences for alternative therapies. N Engl J Med 1982;306:1259-62.

2. Baker DP, Gustafson S, Beaubien JM, et al. Medical team training programs in health care. In: Henriksen K, Battles JB, Marks ES, Lewin DI, Quality. USAfHRa, eds. Advances in patient safety: from research to implementation. Vol 4. Rockville, MD: Agency for Healthcare Research and Quality, 2005: 253-67.

3. King H, Kohsin B, Salisbury ML. Systemwide deployment of medical team training: lessons learned in the department of defense. In: Henriksen K, Battles JB, Marks ES, Lewin DI, Quality. USAfHRa, eds. Advances in patient safety: from research to implementation. Vol 3. Rockville, MD: Agency for Healthcare Research and Quality, 2005:425-35.

4. Fowlkes JE, Lane NE, Salas E, et al. Improving the measurement of team performance: the TARGETs methodology. Mil Psychol 1994;6:47-61.

5. Prince C, Salas E. Training and research for teamwork in the military aircrew. In: Wiener E, Kanki B, Helmreich R, eds. Cockpit resource management. Orlando, FL: Academic Press, 1993:337-66.

6. Stout RJ, Cannon-Bowers JA, Salas E. The role of shared mental models in developing shared situational awareness. In: Gilson R, Garland D, Koonce J, eds.
Situational awareness in complex systems. Daytona Beach, FL: Embry-Riddle Aeronautical University Press, 1993:297-304.

7. Kohn LT, Corrigan J, Donaldson MS. To err is human: building a safer health system. Washington, DC: National Academy Press, 2000.

8. Baker DP, Salas E, King H, et al. The role of teamwork in the professional education of physicians: current status and assessment recommendations. Jt Comm J Qual Patient Saf 2005;31:185-202.

9. Cannon-Bowers J, Salas E, eds. Making decisions under stress: implications for individual and team training. Washington, DC: American Psychological Association Press, 2000.

10. Morey J, Simon R, Jay G, et al. Error reduction and performance improvement in the emergency department through formal teamwork training: evaluation results of the MedTeams project. Health Serv Res 2002;37:1553-80.

11. Shapiro MJ, Morey JC, Small SD, et al. Simulation based teamwork training for emergency department staff: does it improve clinical team performance when added to an existing didactic teamwork curriculum? Qual Saf Health Care 2004;13 417-21.

12. Gaba DM, Howard SK, Fish KJ, et al. Simulation-based training in anesthesia crisis resource management (ACRM): a decade of experience. Simulat Gaming 2001;32:175-93.

13. Thurlow S, Plant M, Muir E. Making teamwork come alive: use of actors and multiprofessional co-leaders in small group teaching about teamwork. Med Educ 2001:35:1081-2.

14. Malec JF, Torsher LC, Dunn WF, et al. Mayo high performance teamwork scale (HPTS): reliability and validity for evaluating key crew resource management skills. Simulat Healthcare 2007:2:4-10.

15. Beaubien JM, Baker DP. The use of simulation for training teamwork skills in health care: how low can you go? Oual Saf Health Care 2004;1(13 Suppl):i51-6.

16. Dillon GF, Boulet JR, Hawkins RE, et al. Simulations in the United States Medica Licensing Examination (USMLE). Oual Saf Health Care 2004;1(13 Suppl):i41-5.

17. Bartels J, Bednash $\mathrm{G}$. Answering the call for quality nursing care and patient safety: a new model for nursing education. Nurs Adm 0 2005;29:5-13.

18. Aspegren K. Teaching and Learning communication skills in medicine-a review with quality grading of articles. Med Teach 1999:21:563-70. 